Graham, N., Mandy, A., Clarke, C., Morriss-Roberts, C., (2017e) Using children and young people as advocates to inform research design. British Journal of Occupational Therapy [accepted for publication July 2017].

Copyright (ㅇ 2017. Reprinted by permission of SAGE Publications. Available at:

\title{
Using children and young people as advocates to inform research design
}

Children and young people informing research

Naomi Graham, MSc, BSc(Hons), PhD student.

University of Brighton, 49 Darley Road, Eastbourne, BN20 7UR, UK

Dr Anne Mandy, PhD, MSc, BSc(Hons), Associate Professor.

University of Brighton, 49 Darley Road, Eastbourne, BN20 7UR UK

Dr Channine Clarke, PhD, MSc, BSc(Hons), Academic lead, Occupational Therapy.

University of Brighton, 49 Darley Road, Eastbourne, BN20 7UR, UK

Dr Christopher Morriss-Roberts, PhD, MA, BSc(Hons), Course Leader MSc Podiatry. University of Brighton, 49 Darley Road, Eastbourne, BN20 7UR, UK

Keywords:

Research Design, Service-user involvement, Child

Conflicts of interest: none to declare 


\section{Using children and young people as advocates to inform research design}

Children and young people informing research

\section{Abstract:}

Statement of context: This practice analysis discusses the benefits and challenges of young advocates with physical disabilities and communication difficulties informing research design.

Critical reflection on practice: The use of advocates helped to inform a PhD project exploring the experience of play for 6-12 year olds with high levels of physical disability due to Cerebral Palsy. This enabled the improvement of the study design in terms of: participant information, interview questions, and the format of the participant interviews.

Implications for practice: Rigorous and well-designed research has a positive impact upon therapy practice. Researchers should make use of children and young people as advocates in order to enable high quality design of research.

\section{Keywords}

Service-user involvement, Child, Research design, Cerebral Palsy

Statement of context The involvement of patients and public within research in the UK is commonly known as PPI (patient and public involvement), a term which is often linked to National Health Service research (Menzies et al. 2016). Internationally, differing terminologies have been used to describe the 
individuals contributing to research: advocates; service users; patients; public; community members; patient and service user engagement (Shipee et al. 2013). The term advocate is defined as 'A person who puts a case forward on someone else's behalf' (Oxford English Dictionary 2017). This term is appropriate for this practice analysis as the two participating individuals were advocating for the best possible research design for the participants within the primary author's PhD study. The study did not take place in a national health context and therefore the term PPI was deemed inappropriate. In order to ensure consistency within this article the term 'advocate' is used to refer to those involved in contributing to research projects. The following practice analysis aims to discuss the involvement of advocates; the contribution of this involvement; and the benefits and challenges of involving advocates within research.

There is a current focus within research to use the perspective of study populations to inform practice, this has led to a trend of involving advocates within study design, particularly prior to ethical committee application (Oliver et al. 2014). Boote et al. (2012) suggest that most advocate involvement is at the point of question identification, it is recommended that communities are consulted prior to deciding research agendas (Pollard et al. 2015). Several models exist recommending more active involvement of advocates throughout the research process (Minogue et al. 2005, Oliver et al. 2014, Shipee et al. 2013). Minogue et al. (2005) discuss different levels of involvement: consultation, collaboration, and user control. At a collaboration level, rather than 
a consultation level, advocates participate in making decisions which actively influence the design of the research (Minogue et al. 2005). This is reiterated by Oliver et al. (2015, p51) who suggests that one of the key aspects of involvement is that the advocate's ideas are 'expressed, understood, integrated, retained, and acknowledged by others'.

\section{Critical reflections on practice:}

The following discussion is based upon the use of advocates within the primary author's PhD project- an Interpretative Phenomenological Analysis of the experience of play for 6-12 year olds with high levels of physical disability due to Cerebral Palsy. Within such research the necessity for high quality and well informed design is emphasised in order that it's of sufficient rigour to inform practice (Abdulai \& Owusu-Ansah 2014). It is possible that an early-stage researcher may initially consult advocates to inform their study design out of a sense of duty rather than a conviction that this will be beneficial (Oliver et al. 2014). This analysis will reflect on in turn- the involvement of advocates; the contribution of this involvement; and the benefits and challenges of involving advocates as a researcher.

\section{The involvement of advocates}

Advocates must first be approached in order to request their involvement with a project. Involvement of individual's directly matching the desired participants could limit the potential sample of participants if the study population is small (McLaughlin 2010). This was the case within the primary researcher's project 
therefore young advocates similar to, but not matching, the study criteria were approached. The advocates within the present project were within the primary researcher's wider social network, they were known through a family friend and student work, they were approached for the pragmatic reason of ease of access. In order to avoid coercion it was made clear that participation within the project was voluntary and both advocates and their parents were consulted prior to their involvement.

Two advocates helped to inform the primary author's research. One was an eight year old, 'Rose' (pseudonym used to protect her identity), functioning at Gross Motor Function Classification System (GMFCS) III (Palisano et al. 2007). The other was a 19 year old, Tim Ford, functioning at GMFCS V. Tim requested and provided written consent for the use of his name, in order that his contribution to the study process is recognised. Both have Cerebral Palsy and make use of Augmentative and Alternative Communication devices.

Involvement of advocates does not require ethical approval as it often starts at the point of study design (Involve 2012). It does however require informed consent and consideration of ethical issues which may impact upon participation within the research process (Brownlie et al. 2006). Both advocates and their parents provided informed written consent for their involvement within the design and process of the research. Rose met with the primary author on one occasion, this extent of involvement was considered to be what was practically possible by both Rose and her parents. Tim met with the primary 
researcher twice prior to ethical approval in order to help finalise the research design; following this, a further meeting and email contact throughout the data analysis process helped the researcher to make sense of, and accurately present the findings.

\section{The contribution of advocate involvement}

One strength of the involvement of advocates is that they provide a unique perspective with regards to health care, service provision, and the experience of the phenomena in question, which influences the design of the research study (Gason et al. 2015, Oliver et al. 2014). Decisions informed by the advocates with regards to the study protocol are summarised in table 1 below; [*insert table 1 below] this clearly demonstrates the successful contribution that both advocates had to the research process. 
Table $1 \mathrm{~A}$ summary of decisions made with regards to the research project following discussion with advocates

\begin{tabular}{|c|c|c|}
\hline $\begin{array}{l}\text { Suggestion from } \\
\text { researcher }\end{array}$ & Advocate response & $\begin{array}{l}\text { Decision made and } \\
\text { reasoning for this }\end{array}$ \\
\hline $\begin{array}{l}\text { The possibility of the } \\
\text { researcher videoing } 5- \\
10 \text { minutes of a play } \\
\text { activity at the start of } \\
\text { each participant } \\
\text { interview. The } \\
\text { possibility of using } \\
\text { visual methods } \\
\text { (drawing, showing of } \\
\text { toys, photos etc.) to } \\
\text { contribute to the depth } \\
\text { of data collected. }\end{array}$ & $\begin{array}{l}\text { When asked about } \\
\text { videoing both advocates } \\
\text { gave an emphatic yes. } \\
\text { Rose- Showed photos } \\
\text { and toys and participated } \\
\text { in drawing in order to } \\
\text { discuss how she thought } \\
\text { play experience should be } \\
\text { captured. }\end{array}$ & $\begin{array}{l}\text { This was agreed as an } \\
\text { appropriate part of the } \\
\text { protocol and discussion } \\
\text { about play. }\end{array}$ \\
\hline $\begin{array}{l}\text { Looked at different } \\
\text { possibilities for } \\
\text { participant information } \\
\text { sheets through designs } \\
\text { and drawings the } \\
\text { researcher had } \\
\text { prepared. }\end{array}$ & $\begin{array}{l}\text { Tim- Commented that a } \\
\text { white background is } \\
\text { hospital like, yellow is } \\
\text { better and more eye } \\
\text { catching for participant } \\
\text { information posters. } \\
\text { Commented that each } \\
\text { poster should use } \\
\text { symbols in order that } \\
\text { participants who use ACC } \\
\text { could read and } \\
\text { understand these better. }\end{array}$ & $\begin{array}{l}\text { Participant information } \\
\text { posters were finalised } \\
\text { following discussion of } \\
\text { different options with Tim } \\
\text { at the second visit prior to } \\
\text { ethical approval. Symbols } \\
\text { and simple sentences } \\
\text { were added for all } \\
\text { information for participants. }\end{array}$ \\
\hline $\begin{array}{l}\text { Discussed the protocol } \\
\text { in terms of how to ask } \\
\text { questions which would } \\
\text { capture play } \\
\text { experiences for the } \\
\text { participants. }\end{array}$ & $\begin{array}{l}\text { Rose- talked about how } \\
\text { participation in some } \\
\text { activities such as going to } \\
\text { Disney land, and making } \\
\text { a fun drink at school were } \\
\text { enjoyable activities to } \\
\text { participate in but weren't } \\
\text { play. }\end{array}$ & $\begin{array}{l}\text { The researcher realised } \\
\text { that questions need to be } \\
\text { carefully phrased in order } \\
\text { that they capture children's } \\
\text { perceptions of play } \\
\text { experience not just } \\
\text { enjoyable activities. }\end{array}$ \\
\hline $\begin{array}{l}\text { Discussed how to make } \\
\text { children feel at ease } \\
\text { and more accurately } \\
\text { capture their } \\
\text { experience. }\end{array}$ & $\begin{array}{l}\text { Rose- found it easier to } \\
\text { talk through quick yes/ no } \\
\text { answers and questions } \\
\text { where there were quick } \\
\text { options. } \\
\text { Tim- discussed at length } \\
\text { the difficulties of adults } \\
\text { not understanding yes/ no } \\
\text { communication and the }\end{array}$ & $\begin{array}{l}\text { The researcher realised } \\
\text { the significance of } \\
\text { communication impairment } \\
\text { and the impact of this on } \\
\text { participation within } \\
\text { interviews. It was decided } \\
\text { that questions such as } \\
\text { 'Can you show me yes?' } \\
\text { and 'Can you show me } \\
\text { no?' would be used at the }\end{array}$ \\
\hline
\end{tabular}




\begin{tabular}{|l|l|l|}
\hline & $\begin{array}{l}\text { impact that this can have } \\
\text { on discussion. }\end{array}$ & $\begin{array}{l}\text { start of each interview and } \\
\text { that short questions would } \\
\text { be used to clarify what was } \\
\text { being chatted about before } \\
\text { the researcher asked more } \\
\text { open questions. }\end{array}$ \\
\hline $\begin{array}{l}\text { Discussed the impact of } \\
\text { CP upon play and how } \\
\text { to best talk about this } \\
\text { with participants. }\end{array}$ & $\begin{array}{l}\text { Tim- referred specifically } \\
\text { to communication } \\
\text { difficulties but did not talk } \\
\text { about physical disability. }\end{array}$ & $\begin{array}{l}\text { The very process of } \\
\text { discussing the impact of } \\
\text { CP upon play enabled the } \\
\text { researcher to realise the } \\
\text { difficulty of phrasing } \\
\text { questions and talking } \\
\text { about disability without } \\
\text { distress. This led to the } \\
\text { inclusion of questions such } \\
\text { as 'What makes you you?' } \\
\text { at the start of the interview } \\
\text { in order that the researcher } \\
\text { could reflect each child's } \\
\text { language or references to } \\
\text { ways that she could } \\
\text { participate in play rather } \\
\text { than the areas that sher } \\
\text { found difficult. } \\
\text { in a way that did not cause } \\
\text { harm. }\end{array}$ \\
\hline $\begin{array}{l}\text { found } \\
\text { Summary of initial } \\
\text { thoughts regarding } \\
\text { analysis was discussed } \\
\text { with Tim. }\end{array}$ & $\begin{array}{l}\text { Tim- feedback that his } \\
\text { early childhood } \\
\text { experience was similar to } \\
\text { what was being discussed } \\
\text { by participants. }\end{array}$ & $\begin{array}{l}\text { This enabled the } \\
\text { researcher to further clarify } \\
\text { analysis and theme } \\
\text { summaries. }\end{array}$ \\
\hline
\end{tabular}

As summarised within the table the advocates made contributions to several stages of the research design which had an influence on the final protocol. Tim also made helpful contributions to the analysis process. Advocates have been seen to enhance the interpretation and consideration of multiple perspectives within the analysis process of an Interpretative Phenomenological Analysis study (Mjøsund et al 2016). Differing approaches are reported within the literature as to the extent of advocate involvement within analysis. Garfield et al. (2016) used an open coding group of 4 advocates to code interviews 
purposively selected by the primary researcher which then contributed to their framework analysis. Within the present study the advocates have not been directly involved in analysing the data, however, the primary researcher has found that in discussing the emerging themes and subthemes with Tim they have resonated with his experience. This has led to helpful consideration with Tim as to how to phrase and adequately express these interpretations.

\section{Benefits and challenges for the researcher}

It was of benefit to the researcher that advocates were previously known and therefore easily contactable; this is a pragmatic approach Occupational Therapists can take as long as they are careful to following ethical guidelines. Alternatively, other researchers involving children and young people as advocates have approached pre-existing groups (Watson et al. 2012); young people older than the study population through a charity (Payne 2016); and parents together with their children (Menzies et al. 2016).

Although the communication difficulties of the study population presented a challenge to the research design, the involvement of advocates with communication difficulties was of significant benefit to the researcher. Bailey et al. (2014) suggest that children with disabilities are less likely to be involved in research, they encourage greater efforts to include advocates with communication difficulties. Both advocates informing the primary researcher's study have communication difficulties which led to important design considerations. Tim uses a head-switch activated communication device and 
body language to indicate 'yes' and 'no'. The opportunity to talk to him about the study gave the invaluable experience of having a detailed discussion with someone using a communication device. Although the primary researcher had experience of this within occupational therapy practice, meeting with the advocates to discuss the research was considerably different. This was due to the differences in communicating in the context of a therapy activity, which felt easier in comparison to meeting to discuss a complex concept. This led to the realisation that activities can enable depth of discussion; the subsequent use of pictures, toys and videos as part of the study protocol meant that the study participants could more easily discuss the concept of play. Discussions with advocates also enabled the primary researcher to practice creating depth of discussion which does not occur in a goal driven therapy session.

One difficulty with involving advocates, particularly as a practitioner experienced in a field, is that changes suggested by advocates may not always be the most beneficial or appropriate for the research in the opinion of the researcher (Oliver et al. 2015). Rose and Tim had several helpful suggestions for the study design, but some suggestions could not be carried out as proposed. For example, the suggestion to use labelled beanbags for children to throw in order to make a comment was considered impractical due to the difficulty the participants would have with manipulating these. Despite this, each suggestion, even when impractical, enabled the primary researcher to consider different options and possibilities for study design. Alternative methods of communication, such as eye-pointing to a beanbag the researcher could throw, 
were considered. This led to further exploration and discussion of practical methods such as using videos and creating play drawings, which would enable participants to communicate their experience.

Consideration of the interview format and discussion around communication also led to a significant change to the interview transcription process. This had not been previously considered but it became apparent that if children were using body language to communicate 'yes' and 'no', and also to provide expression alongside their computerised voice, this needed to be captured within the transcript. This led to the decision to video record each interview. Video records of the interviews have enabled each child's communication to be sufficiently captured for transcription. Without discussion about communication with advocates it is unlikely that this would have been a planned part of the research design. This could have led to several delays in the research process in re-applying for ethics or difficulties with interpretation at the transcription and analysis stages because of lack of clarity of participant meaning. This is supported by the research literature where there is a recognition that changes in the research protocol upon the advice of advocates can lead to research with greater rigour, feasibility and relevance (Oliver et al. 2014). Increasingly researchers are aiming to improve the involvement of individuals who have traditionally been less widely used to inform research (Nind et al. 2015). In particular there has been a urge to involve children and young people 
with disabilities in active meaning making through the research process (Nind et al. 2010). Researchers have successfully involved young people with disabilities as advocates for study design and dissemination (Watson \& Felier 2012, Brownliee et al. 2006). This practice analysis provides an illustration of successful involvement of a child, and of individuals with both communication and physical disabilities. The positive outcomes of involving young advocates with disabilities within the present study suggests that the urge to involve those who are less widely used to inform research is well founded.

\section{Summary:}

There is a consensus that advocates can have a positive impact upon research, yet this needs to be more accurately measured (Staley et al. 2012). The present study did not set specific outcomes or measure the involvement of advocates within this study. However, this practice analysis demonstrates the benefits that the advocates have had in relation to the design and process of the research project. Such involvement highlights the possibility of working collaboratively with individuals who would be considered vulnerable because of their age and disability in a way that has a positive impact. This has particular relevance to occupational therapy researchers who may be looking to conduct research with vulnerable populations. The use of advocates who are similar to the potential study population is therefore recommended.

\section{Key Messages:}


- Involvement of young advocates with physical disabilities and communication difficulties was helpful to research study design.

- Occupational therapy researchers should involve advocates at a collaborative level throughout the research process.

All participants and their parents provided written informed consent.

The Authors confirm that there is no conflict of interest.

This research received no specific grant support from any funding agency in the public, commercial, or not-for-profit sectors.

The Authors Acknowledge the involvement of Tim Ford and 'Rose' as part of the research process. 


\section{References}

Abdulai RT, and Owusu-Ansah A (2014) Essential Ingredients of a Good Research Proposal for Undergraduate and Postgraduate Students in the Social Sciences. Sage Open 1-15.

Bailey S, Boddy K, Briscoe S, Morris C (2014) Involving disabled children and young people as partners in research: a systematic review. Child: care, health and development 41 (4): 505-514.

Boote J, Wong R, Booth A (2012) 'Talking the talk or walking the walk?' A bibliometric review of the literature on public involvement in health research published between 1995 and 2009. Health expectations 18: 44-57.

Brownlie J, Anderson S, Ormsto R (2006) Children as Researchers.

Edinburgh: Scottish Executive Social Research.

Garfield S, Jheeta S, Husson F, Jacklin A, Bischler A, Norton C, Franlin BD (2016) Lay involvement in the analysis of qualitative data in health services research: a descriptive study. Research Involvement and Engagement 2(2): $1-12$.

Gason S, Bliss J, Jamal-Hanjani M, Krebs M, Swanton C, Wilcox M (2015) The value of patient and public involvement in trial design and development. Clinical Oncology 27: 747-479. 
Involve (2012) Briefing notes for researchers: public involvement in NHS, public health and social care research. London: National Institute for Health Research. Accessed at: http://www.invo.org.uk/

Minogue V, Boness J, Brown A, Girdlestone J (2005) The impact of service user involvement in research. International Journal of Health Care Quality Assurance 18(2):103-11.

McLaughlin H (2010) Keeping Service User Involvement in Research Honest. British Journal of Social Work 40, 1591-1608

Menzies JC, Morris KP, Duncan HP, Marriott JF (2016) Patient and public involvement in Paediatric Intensive Care research: considerations, challenges and facilitating factors. Research Involvement and Engagement 2:32: 1-16.

Mjøsund NH, Eriksson M, Espnes GA, Haaland-Øverby M, Jensen SL, Norheim N, Høymork Kjus SH, Portaasen I, Vinje HA (2016) Service user involvement enhanced the research quality in a study using Interpretive Phenomenological Analysis- the power of multiple perspectives. Journal of Advanced Nursing June, 1-14.

Nind M, Chapman R, Seale J, Tilly L (2015) The Conundrum of Training and Capacity Building for People with Learning Disabilities Doing Research. Journal of Applied Research in Intellectual Disabilities October, 1-10. 
Nind M, Flewitt R, Payler J (2010) The social experience of early childhood for children with learning disabilities: inclusion, competence and agency. British Journal of Sociology of Education 31:6, 653-670.

Oliver S, Liabo K, Stewart R, Rees R (2014) Public involvement in research: making sense of the diversity Journal of Health Services Research and Policy. 20(1):45-51

Oxford English Dictionary (2017) Oxford: Oxford University Press. Available at: https://en.oxforddictionaries.com/definition/advocate

Palisano R, Rosenbaum P, Bartlett D, Livingston M (2007) Gross Motor Function Classification System- expanded and revised. CanChild Centre of Childhood Disability Research, McMaster University: Canada.

Payne S (2016) Conference presentation. Challenging the Boundaries:

European Academy of Childhood disability. Stockholm, Sweeden.

Pollard K, Donskoy AL, Moule P, Donald C, Lima M, Rice C (2015)

Developing and evaluating guidelines for patient and public involvement (PPI) in research International Journal of Health Care Quality Assurance, 28 (2), 141-155.

Shipee ND, Domecq Garces JP, Prutsky Lopez GJ et al. (2013) Patient and service user engagement in research: a systematic review and synthesized framework. Health Expectations 18:1151-1166. 
Staley K, Buckland SA, Hayes H, Tarpey M (2012) 'The missing links': understanding how context and mechanism influence the impact of public involvement in research. Health Expectations 17: 755-764.

Watson D, Feiler A (2012) Involving young disabled people in the research process: The experiences of the PIE research project team Children \& Society, May:1-11. 